A few complex fluids display the opposite effect when sheared between plates: they develop a tension across the flow direction that draws the plates together — that is, a negative $N_{1}$ (Fig. 1b). Liquid-crystalline polymers, such as the precursors of the Kevlar and Zylon high-performance fibres, are the best known class of liquids to display such negative $N_{1}$ (ref. 4), although the phenomenon has been observed occasionally in concentrated suspensions ${ }^{5}$, emulsions ${ }^{6}$, and also in liquid-crystalline dispersions of single-walled $\mathrm{CNTs}^{7}$ as well as in dispersions of multiwalled CNTs in a lowmolecular-weight solvent ${ }^{8}$. The origin of negative $N_{1}$ is not clear, although it has been linked with flow-induced phase separation and striping in the direction perpendicular to the flow plane in a few cases $^{6,8}$.

As positive $N_{1}$ is related to die swell in extrusion, negative $N_{1}$ is related to a contraction of the fluid exiting the die. This had been demonstrated in the case of highly concentrated suspensions ${ }^{5}$ (above $50 \%$ solids), but had never been brought to bear in practical applications. Now, Kharchenko and co-workers ${ }^{2}$ have shown that this rare effect can be induced at will by adding a small amount of multiwalled CNTs to a common polymer, and that this can be exploited to eliminate die swell. Thus, CNTs can be used as processing aids while at the same time improving the final properties (in this case the electrical conductivity) of the solid material: this is unusual, because good properties and easy processing do not often marry together.

The work of Kharchenko et al. ${ }^{2}$, together with other recent reports of negative $N_{1}$ (refs 5-8), will surely generate practical as well as theoretical interest. On the practical side, it is possible that similar effects may be obtained by dispersing fibres other than CNTs in polymers, which will impact the field of fibre-reinforced composites. It will be interesting to find operating windows for the extrusion of polymer-fibre composites that show negative $N_{1}$. This could be done by checking if processing instabilities, such as the surface fracturing of a polymeric extrudate, are delayed or eliminated by controlling the extent of the negative $N_{1}$, as recent work suggests ${ }^{9}$, and by determining whether high extrusion speed can degrade electrical properties by aligning the CNTs and disrupting the CNT network. On the theoretical side, the cause of negative $N_{1}$ in several classes of complex fluids ultimately needs to be explained and related to the fluid microstructure, and possibly other variables such as the strength of the flow and the presence of confining surfaces. Of course, such theoretical understanding will also be invaluable in designing optimal formulation and processes for soft nanostructured materials.

\section{References}

1. Baughman, R. H., Zakhidov, A. A. \& de Heer, W. A. Science 297, 787-792 (2002).

2. Kharchenko, S. B., Douglas, J. F., Obrzut, J., Grulke, E. A. \& Migler, K. B. Nature Mater. 3, 564-568 (2004).

3. Larson, R. G. The Structure and Rheology of Complex Fluids (Oxford Univ. Press, New York, 1999).

4. Kiss, G. \& Porter, R. S. J. Polym. Sci. B 18, 361-388 (1980).

5. Aral, B. K. \& Kalyon, D. M. J. Rheol. 41, 599-620 (1997).

6. Montesi, A., Peña, A. A. \& Pasquali, M. Phys. Rev. Lett. 92, 058303 (2004).

7. Davis, V. A. et al. Macromolecules 37, 154-160 (2004)

8. Lin-Gibson, S., Pathak, J. A., Grulke, E. A., Wang, H. \& Hobbie, E. K. Phys. Rev. Lett. 92, 048302 (2004)

9. Meulenbroek, B. et al. Phys. Rev. Lett. 90, 024052 (2003).

\title{
MATERIALWITNESS Faux food to the rescue?
}

T

old that I wanted to study

chemistry, my school careers

adviser suppressed an

expression of panic to suggest

that there were opportunities for

chemists in frozen foods. My father was

not a scientist of any sort, but he discerned

with disdain that food science wasn't

exactly at the cutting edge of research, a

judgement with which I concurred.

But now I wonder. In a recent essay

(http://www.prospect-magazine.co.uk/

start.asp?P_Article=12702), political analyst Michael Lind

argues that all the world's predicted future population of

9 million might achieve the living standard of developed

nations without despoiling our planet. Indeed, Lind thinks

that it may be possible for such a global society to coexist

with larger areas of wilderness than are preserved today.

Lind's Panglossian arguments invite copious criticism;

but how does he propose to realise this miracle anyway?

New technology is the main answer. "Sometimes", Lind

says, "there really are technical fixes." The owner of a ranch

in Texas, Lind makes agriculture one of his primary

concerns. How will we feed $9 \mathrm{~m}$ people especially as greater

affluence is accompanied by an increased meat intake?

"A pasture and a cow", Lind admits, "is an extremely

inefficient way to convert soil, water and sunlight into

a steak."

What's the alternative? "I would rather eat a nutritious pork chop from a laboratory test tube than from a pig which

had spent its life drugged in a tiny cage caked with its own waste", Lind argues. By making meat artificially, we would

liberate masses of land that can revert to wilderness.

It is a truly Baconian vision, in which food is made "entirely

from raw materials and artificial energy in a subterranean

food factory". Nigel Calder, former editor of New Scientist,

talked in his book The Environment Game (1967) about

"nourishing but unpalatable primary food produced by

industrial techniques". But Calder envisaged this as animal

feed, not for human consumption. For us, it would have to be

palatable too.

Nonetheless, the image this invokes is of trays of

'astronaut food', with all the right nutrients but frankly as

appealing as baby food. That is where the materials

expertise of food scientists enters. There is now plenty of

research showing how the texture of food affects the

sensory experience - the pleasure - of eating it.

(See, for example, J. Agric. Food Chem. 50, 5149; 2002.)

Clever engineering of processed foods could make bland,

'plastic' cheese and meat substitutes a thing of the past.

I am not sure I'Il ever be a convert: I take Lind's point that free-range livestock is potentially (if not inevitably)

wasteful of land, but I do wonder whether he has tasted the

difference between a free-range and a battery-reared

chicken. On the other hand, as a lapsed vegetarian I do feel

some eagerness for food scientists to perfect the texture of

faux sausages and bacon. It should not be hard to make

food substitutes nutritious; the greater trick will be to make

these things acceptable to food snobs. Food scientists

may be unglamorous, but chefs are today's rock stars.

Which of them will be first to make a gourmet dish from

artificial meat?

Philip Ball 